\title{
Cardiovascular magnetic resonance imaging of functional and microstructural changes of the heart in a longitudinal pig model of acute to chronic myocardial infarction
}

\author{
Christian T. Stoeck ${ }^{1,3}$, Constantin von Deuster ${ }^{1}$, Maximilian Fuetterer ${ }^{1}$, Malgorzata Polacin ${ }^{1,2}$, \\ Conny F. Waschkies ${ }^{1,3}$, Robbert J. H. van Gorkum', Mareike Kron³ ${ }^{3}$ Thea Fleischmann³, Nikola Cesarovic 3,4, \\ Miriam Weisskopf ${ }^{3}$ and Sebastian Kozerke ${ }^{1 *}$ (1)
}

\begin{abstract}
Background: We examined the dynamic response of the myocardium to infarction in a longitudinal porcine study using relaxometry, functional as well as diffusion cardiovascular magnetic resonance (CMR). We sought to compare non contrast CMR methods like relaxometry and in-vivo diffusion to contrast enhanced imaging and investigate the link of microstructural and functional changes in the acute and chronically infarcted heart.

Methods: CMR was performed on five myocardial infarction pigs and four healthy controls. In the infarction group, measurements were obtained 2 weeks before 90 min occlusion of the left circumflex artery, 6 days after ischemia and at 5 as well as 9 weeks as chronic follow-up. The timing of measurements was replicated in the control cohort. Imaging consisted of functional cine imaging, 3D tagging, T2 mapping, native as well as gadolinium enhanced T1 mapping, cardiac diffusion tensor imaging, and late gadolinium enhancement imaging.

Results: Native T1, extracellular volume (ECV) and mean diffusivity (MD) were significantly elevated in the infarcted region while fractional anisotropy (FA) was significantly reduced. During the transition from acute to chronic stages, native T1 presented minor changes $(<3 \%)$. ECV as well as MD increased from acute to the chronic stages compared to baseline: ECV: $125 \pm 24 \%$ (day 6) 157 $\pm 24 \%$ (week 5) 146 $\pm 60 \%$ (week 9), MD: $17 \pm 7 \%$ (day 6) 33 $\pm 14 \%$ (week 5) $29 \pm 15 \%$ (week 9) and FA was further reduced: $-31 \pm 10 \%$ (day 6 ) $-38 \pm 8 \%$ (week 5) $-36 \pm 14 \%$ (week 9). T2 as marker for myocardial edema was significantly increased in the ischemic area only during the acute stage $(83 \pm 3 \mathrm{~ms}$ infarction vs. $58 \pm 2 \mathrm{~ms}$ control $p<0.001$ and $61 \pm 2 \mathrm{~ms}$ in the remote area $p<0.001)$. The analysis of functional imaging revealed reduced left ventricular ejection fraction, global longitudinal strain and torsion in the infarct group. At the same time the transmural helix angle (HA) gradient was steeper in the chronic follow-up and a correlation between longitudinal strain and transmural HA gradient was detected $(r=0.59$ with $p<0.05)$. Comparing non-gadolinium enhanced data T2 mapping showed the largest relative change between infarct and remote during the acute stage $(+33 \pm 4 \%$ day 6 , with $p=0.013$ T2 vs. MD, $p=0.009$ T2 vs. FA and $p=0.01$ T2 vs. T1) while FA exhibited the largest relative change between infarct and remote during the chronic follow-up $(+31 \pm 2 \%$ week 5 , with $p=N$.S. FA vs. MD,
\end{abstract}

\footnotetext{
*Correspondence: kozerke@biomed.ee.ethz.ch

${ }^{1}$ Institute for Biomedical Engineering, University and ETH Zurich, Gloriastrasse 35, 8092 Zurich, Switzerland
}

Full list of author information is available at the end of the article

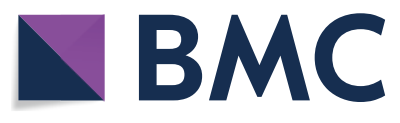

(c) The Author(s) 2021. Open Access This article is licensed under a Creative Commons Attribution 4.0 International License, which permits use, sharing, adaptation, distribution and reproduction in any medium or format, as long as you give appropriate credit to the original author(s) and the source, provide a link to the Creative Commons licence, and indicate if changes were made. The images or other third party material in this article are included in the article's Creative Commons licence, unless indicated otherwise in a credit line to the material. If material is not included in the article's Creative Commons licence and your intended use is not permitted by statutory regulation or exceeds the permitted use, you will need to obtain permission directly from the copyright holder. To view a copy of this licence, visit http://creativecommons.org/licenses/by/4.0/. The Creative Commons Public Domain Dedication waiver (http://creativeco mmons.org/publicdomain/zero/1.0/) applies to the data made available in this article, unless otherwise stated in a credit line to the data. 
$p=0.03$ FA vs. T2 and $p=0.003$ FA vs. T1). Overall, diffusion parameters provided a higher contrast ( $>23 \%$ for MD and $>27 \%$ for FA) during follow-up compared to relaxometry (T1 17-18\%/T2 10-20\%).

Conclusion: During chronic follow-up after myocardial infarction, cardiac diffusion tensor imaging provides a higher sensitivity for mapping microstructural alterations when compared to non-contrast enhanced relaxometry with the added benefit of providing directional tensor information to assess remodelling of myocyte aggregate orientations, which cannot be otherwise assessed.

Keywords: Chronic myocardial infarction, Microstructural CMR, Functional CMR, CMR Relaxometry, $T_{2}$ mapping, $T_{1}$ mapping, ECV, DCE, LGE, Cardiac DTI

\section{Background}

The loss of functional cardiac tissue due to myocardial infarction (MI) can lead to ventricular remodeling including myofiber disarray, myocardial wall thinning and dilatation compromising left ventricular (LV) function $[1,2]$. Without timely treatment, these conditions often progress towards clinical heart failure [3, 4].

The response to an ischemic event has been characterized as a dynamic process [5]. During the first hours, reperfusion-related edema leads to swelling of injured myocardium, followed by a period of reduced swelling during the subsequent days with collagen deposition, leading to a second wave of inflammatory edema associated with healing [6]. The degradation of cell membranes and vasculature in the ischemic region results in an elevated extracellular volume fraction (ECV) [7], which increases the residence time of gadolinium-based contrast agents as detected by late gadolinium-enhancemed (LGE) imaging [8]. The successive LV remodelling is characterized by ventricle enlargement and increase in LV sphericity [9].

Non-viable infarcted tissue leads to an increase in the cardiac workload of the remaining viable myocardium and subsequently to compensatory hypertrophy [10]. In addition, ventricular dilation may be considered as a compensatory response to maintain stroke volume in the presence of declining ejection fraction through the Frank-Starling mechanism [11]. While this compensatory process may be viewed as a positive response to keep up blood supply to the systemic circulation, it leads to increasing systolic and diastolic wall stresses, which stimulate further ventricular remodelling [12]. Among patients studied 2 to 4 weeks after an acute MI, those who developed a spherical ventricle appeared to have a greater propensity for the development of heart failure [13]. Similarly, an increase of LV volume is associated with poor long-term prognosis [14].

With changes in LV shape, alterations in function have been reported: Global longitudinal strain (GLS), global radial strain (GRS) and global circumferential strain (GCS) were found to be significantly decreased in magnitude in patients with MI when compared with controls
[15]. While all three strain indices are impaired in MI patients, GLS was found to be the strongest predictor for major adverse cardiac events (MACE) [16] and most consistently detected the change in remodelled LVs during follow-up across different studies [17]. Besides characterizing the tissue deformation by strain measurements, rotation, twist and torsion have been analysed as functional marker in MI patients. Patients who developed LV remodeling at a 6 month follow-up showed significantly impaired peak subepicardial and subendocardial twist compared to patients without remodeling [18]. The impact on LV rotational patterns is, however, dependent on infarct location. The apical rotation was found to be lower in patients with acute anterior compared with acute inferior MI, while vice versa for basal rotation. As consequence, overall LV torsion was not significantly different between the two infarct groups [19].

The changes in shape and function coincide with changes in tissue composition that can be assessed by cardiovascular magnetic resonance (CMR) relaxometry. Edema present during the acute stage after myocardial ischemia/reperfusion injury [6] is associated with significantly increased T2 relaxation times. During the chronic post-MI stages, dead cardiomyocytes are replaced by extracellular matrix resulting in chronically increased ECV. By measuring pre- and post-contrast $\mathrm{T} 1$ values in conjunction with sampling the patient's haematocrit, this increase in ECV can be quantified [20].

Complementary to measuring changes in relaxation times, cardiac diffusion tensor imaging (cDTI) has become an important tool to non-destructively probe changes of microstructure in the anisotropic myocardium. cDTI provides parameters such as mean diffusivity (MD) and fractional anisotropy (FA), thereby granting insights into the structural integrity of tissue, as well as spatially directional parameters such as the inclination angle of cardiomyocyte aggregates, also known as helix angle. In the realm of MI, an elevated MD and a reduced FA was found within the affected region due to loss of tissue integrity resulting in fewer restrictions to water molecules and providing a prolonged mean free pathway [21-23]. In the chronic stage, structural 
remodelling in the remote zone was found in pigs with permanent left-anterior descending (LAD) or left circumflex (LCX) coronary artery occlusion, reflected in an increase of left-handed myocyte aggregates (epicardium) in conjunction with a decrease in right-handed myocyte aggregates (endocardium) [22]. However, only differences in the cases of LAD occlusion were statistically significant. Similar studies in sheep [24] and patients [25] with chronic MI did not find statistically significant changes in the handedness of the microstructural architecture. Furthermore, the myocyte propagation angle has shown good spatial correlation with LGE imaging in mice and patients with MI. Areas with scar showed increased variability when tracking the principal direction of myocyte aggregates [26].

Relaxometry as well as cDTI both assess tissue alterations that occur at the microscopic level. While T2 and T1 mapping reflect changes in spin-spin and spin-lattice relaxation that are influenced by water content and macromolecular environment, while cDTI is sensitive to changes of water self-diffusion that is governed by the presence and architecture of restrictions such as cell membranes.

In the present work, we present a longitudinal swine study to compare relaxometry and cDTI during the dynamic response of the myocardium to MI from the healthy to the acute and chronic MI stages. Using the longitudinal multi-parametric study design, we furthermore exploit the capability of cDTI to derive information on myocyte aggregate orientation to potentially link microstructural changes due to microstructural remodelling with functional alterations in the infarcted heart over time.

\section{Methods}

Nine healthy female swine (Swiss Large White "Edelschwein", 30-35 kg) were imaged on a clinical 1.5T CMR system (Achieva, Philips Healthcare, Best, The Netherlands) equipped with a gradient system delivering $80 \mathrm{mT} / \mathrm{m}$ per physical axis at a slew rate of $100 \mathrm{~T} / \mathrm{m} / \mathrm{s}$.

The study was approved by the veterinary office of the canton of Zurich under licence: ZH072/16.

\section{Animal handling}

All experimental procedures were performed under general anaesthesia. The pigs were pre-medicated with an intramuscular injection of ketamine $(15 \mathrm{mg} / \mathrm{kg}$, Ketasol ${ }^{\circledR}-100$, Graeub AG, Bern Switzerland), azaperone $\left(2 \mathrm{mg} / \mathrm{kg}\right.$, Stresnil ${ }^{\circledR}$, Elanco Tiergesundheit AG, Basel Switzerland) and atropine $(0.05 \mathrm{mg} / \mathrm{kg}$, Atropin 1\% Kantonsapotheke, Zurich Switzerland). An intravenous catheter was placed and anaesthesia was deepened with propofol (Propofol-Lipuro $2 \mathrm{mg} / \mathrm{kg}$, B. Braun
Medical AG, Sempach, Switzerland) followed by orotracheal intubation. Percutaneous sheaths (5F) were introduced into the femoral arteries and veins. $100 \mathrm{IU} / \mathrm{kg}$ body weight (BW) heparin was administered intravenously and was repeated every hour. General anaesthesia was maintained with isoflurane $(2-3 \%)$ by positive pressure ventilation with $100 \%$ oxygen. Heart rate and rhythm and variability (ECG), inspiratory and expiratory gases $\left(\mathrm{CO}_{2}\right.$, $\mathrm{O}_{2}$, isoflurane), pulse oximetry, temperature, direct arterial blood pressure and urine output were monitored continuously throughout the procedure. Arterial blood gas analysis was performed hourly to assess gases $\left(\mathrm{pO}_{2}\right.$, $\left.\mathrm{pCO}_{2}\right)$, electrolyte balance $\left(\mathrm{Na}^{+}, \mathrm{K}^{+}, \mathrm{Ca}^{2+}, \mathrm{Cl}^{-}\right)$, haematocrit as well as glucose, lactate and creatinine. Additionally, high-sensitive Troponin $\mathrm{T}$ (hsTnT) levels were measured according to study time points. Analgesia was provided by administration of buprenorphine $(0.01 \mathrm{mg} /$ $\mathrm{kg})$ every $4-6 \mathrm{~h}$ throughout the procedure and by meloxicam $(0.4 \mathrm{mg} / \mathrm{kg})$ orally for 2 days.

Before MI induction, animals received antiarrhythmic medication [150 mg amiodarone (Cordarone ${ }^{\circledR}$, SanofiAventis, Paris, France) dissolved in $100 \mathrm{ml} \mathrm{5 \%} \mathrm{glucose}$ solution]. For cardiac synchronization of the imaging sequences, ECG electrodes (Quatrode patch, In-Vivo Corporation, Gainesville, Florida, USA) were placed onto the chest between the front limbs.

After the final CMR measurement (week 9) the animals were euthanized by an overdose of pentobarbital $(75 \mathrm{mg} /$ $\mathrm{kg}$ BW iv) in deep anaesthesia.

\section{Study protocol}

Animals were grouped into MI $(\mathrm{N}=5)$ and control $(\mathrm{N}=4)$ cohorts. Animals in the MI group underwent baseline imaging 15 days before MI, had an MI induced on day 0 and were followed up during the acute stage at day 6 after MI and twice during follow-up i.e. at in week 5 at 34 days and in week 9 at 62 days post MI. The control group underwent CMR at the same time points as the MI group.

The MI group underwent one additional anaesthesia for induction of MI by 90 min occlusion of the LCX with a balloon catheter 15 days after baseline imaging (day 0 ). The additional anaesthesia and intervention were not performed in the control group.

\section{Imaging protocol \\ Functional imaging and strain analysis}

Two- and four-chamber long-axis cine CMR was performed in addition to multi-slice short-axis cine imaging. Image acquisition was performed during ventilated breathing with the following imaging parameters: 
$1.8 \times 1.8 \mathrm{~mm}^{2}$ spatial resolution, $8 \mathrm{~mm}$ slice thickness, 25 heart phases, $1.5 \mathrm{~ms} / 3 \mathrm{~ms} \mathrm{TE} / \mathrm{TR}, 45^{\circ}$ flip angle.

LV end-diastolic and end-systolic volumes (LVEDV/ LVESV), ejection fraction (LVEF) as well as stroke volume (SV) were computed using commercial software (ISP, Philips Healthcare).

GRS, GCS and GLS were computed using Segment CMR (Medviso, Lund, Sweden).

\section{Tagged imaging and evaluation of torsion}

3D tagged imaging was performed acquiring three stacks [27] with orthogonal complementary spatial modulation of magnetization (CSPAMM) tagging [28] using the following imaging parameters: $2 \times 2 \times 5 \mathrm{~mm}^{3}$ spatial resolution, $110 \times 110 \times 110 \mathrm{~mm}^{3}$ field-of-view, 26 heart phases, $4 \mathrm{~mm}$ tagline distance, $4.3 \mathrm{~ms} / 9.2 \mathrm{~ms} \mathrm{TE} / \mathrm{TR}$, turbo factor 3, echo planar imaging (EPI) factor 7.

Tagged data was analysed using a 3D SinMod [29] based algorithm implemented in GTTagTrack (GyroTools LLC, Winterthur, Switzerland). For each slice position, a mid-mural contour was manually drawn and tracked over time. The rotation of each contour around the centre axis was plotted against the initial longitudinal position and a linear regression was consequently performed. The slope of the linear fit was computed to represent left-ventricular torsion/twist per unit length [30].

\section{Mapping}

T1 and T2 mapping were performed during suspended ventilation. T1 mapping was obtained using a modified Look-Locker inversion recovery sequence (MOLLI) [31] with the following imaging parameters: $2 \times 2 \mathrm{~mm}^{2}$ spatial resolution, $8 \mathrm{~mm}$ slice thickness, $1.1 \mathrm{~ms} / 2.3 \mathrm{~ms}$ TE/TR, 10-13 (pre-contrast) or 12-14 (post-contrast) inversion delays depending on the heart rate. T1 MOLLI was performed before and $20 \mathrm{~min}$ after administration of $0.2 \mathrm{mmol} / \mathrm{kg}$ gadolinium-based contrast agent. For T2 mapping a multi-echo spin-echo sequence with multi-shot EPI readout was acquired with the following parameters [32]: $2 \times 2 \mathrm{~mm}^{2}$ spatial resolution, $10 \mathrm{~mm}$ slice thickness. Nine echoes with a $\Delta \mathrm{TE}$ of $8.8 \mathrm{~ms}$ were sampled.

Native and post-contrast T1 maps, ECV maps as well as T2 maps were reconstructed upon image registration using an in-house Matlab (Mathworks, Natick Massachusetts, USA) tool [33] and manually segmented using GTVolume (GyroTools, Winterthur, Switzerland).

\section{Cardiac diffusion tensor imaging}

In-vivo cDTI was performed using a second-order motion-compensated spin echo sequence [34, 35]. The trigger delay (time between detection of R-wave and first radiofrequency pulse) was set to $65 \%$ of peak contraction [35-37] and data were acquired during ventilated breathing. Imaging parameters were: $2 \times 2 \mathrm{~mm}^{2}$ spatial resolution, $8 \mathrm{~mm}$ slice thickness, TE/TR: $81 \mathrm{~ms} / 5 \mathrm{R}-\mathrm{R}$ intervals, three diffusion encoding directions @ $\mathrm{b}=100 \mathrm{~s} / \mathrm{mm}^{2}$, three diffusion encoding directions @ $b=200 \mathrm{~s} / \mathrm{mm}^{2}$ and 12 diffusion encoding directions @ $b=450 \mathrm{~s} / \mathrm{mm}^{2}$. Eight signal averages were obtained. In total 10 slices were acquired in packages of five slices in an interleaved fashion. The FOV was limited in phase encoding direction using non-coplanar excitation [38]. The total acquisition duration including preparation phases was approximately $28 \mathrm{~min}$ (at $60 \mathrm{bpm}$ ).

Diffusion parameters were computed using an in-house Matlab tool including non-rigid image registration and fitting the diffusion tensor to the cDWI data. MD, FA as well as the transmural change in helix angle (HA) were quantified. The HA was computed after projection of the tensor's first eigenvector onto the longitudinal-circumferential surface as the angle between the resulting projection and the local circumferential direction according to [37]. The local radial, circumferential and longitudinal directions were calculated as described in [37]. Due to the thin wall at the location of MI, the transmural change of HA was computed in the remote area only i.e. in the septal segment (corresponding to American Heart Association segments 8 and 9 [39]). The myocardium was carefully segmented to avoid inclusion of right ventricular tissue [40].

\section{Late gadolinium enhancement}

LGE scar imaging was performed with a 3D inversionrecovery gradient-echo sequence approximately $15 \mathrm{~min}$ after contrast injection. The inversion time was adjusted to null non-infacted myocardial signal. Imaging parameters were: $2 \times 2 \times 8 \mathrm{~mm}^{3}$ spatial resolution, $1.4 \mathrm{~ms} / 2.8 \mathrm{~ms}$ TE/TR, turbo factor 20.

Infarct mass was quantified using clinical software (ISP, Philips Healthcare) based on intensity thresholding at five standard deviations of non-enhanced remote tissue signal followed by manual refinement. Scar mass is reported as percentage of the total myocardial mass.

\section{Statistics}

Scalar values were averaged across the region of interest (infarction/remote zone) and statistically significant differences were tested for by either paired (infarction vs. remote zone in the same animal) or unpaired (remote zone in infarct animals vs. control animals) two-tailed Student's t-test. A $p$-value smaller than 0.05 was considered statistically significant. 
Diffusion (MD, FA) parameters were correlated to relaxometry (T1, T2) parameters and ECV values. Similarly, transmural change in HA was compared to strains and torsion.

For relaxometry mapping and diffusion parameters, the relative change in parameter was computed as paired difference between remote and infarcted area normalized by the values of the remote area. In order to evaluate any potential bias in the remote area, values were compared to healthy control data. To this end, differences between the remote area in infarcted animals and the same area in control animals were computed for all possible pairs of control and infarcted animals. The reported differences are normalized to the average of control and remote data.

\section{Results}

All animals showed normal growth and weight gain during the longitudinal study programme: from $32 \pm 2 / 29 \pm 4 \mathrm{~kg}$ (baseline at -15 days) to $43 \pm 4 / 41 \pm 6 \mathrm{~kg}$ (day 6), $58 \pm 5 / 56 \pm 5 \mathrm{~kg}$ (week 5) and $73 \pm 6 / 72 \pm 6 \mathrm{~kg}$ (week 9) for control/MI groups. LV mass, LVEF, LVEDV, LVESV and SV as well as hsTnT are listed in Table 1.

LV mass, LVEDV, LVESV as well as SV continuously increased over the course of the experiment in both study cohorts. While LVEF remained in a range of $51-56 \%$ in the control group, it was reduced to $43-47 \%$ after MI. The reduction in LVEF in the MI group was associated with continuously increasing LVESV over the duration of the experiment, above the values expected from growth in the controls. The relative size of the ischemic region based on LGE was $11 \pm 4 \%$ (day 6 ), $12 \pm 4 \%$ (week 5 ) and $11 \pm 4 \%$ (week 9). The corresponding infarct mass was: $5.7 \pm 2.5 \mathrm{~g}$ (day 6), $7.6 \pm 3.0 \mathrm{~g}$ (week 5) and $8.8 \pm 4.0 \mathrm{~g}$ (week 9).

Figure 1 shows example images of one infarct study animal over the time course of the experiment: baseline (15 days before MI) and 6 days, 5 weeks and 9 weeks after MI. The end-systolic time frame of the cine image series showed an area of hypo-contraction in the inferior lateral wall between the papillary muscles, which coincides with LGE signal enhancement. T2 values were elevated in the ischemic region at day 6 and correspondingly ECV maps showed clear enhancement during chronic follow-up. The areas of elevated MD and reduced FA were co-located with the infarcted segment. The transmural variation of myocyte aggregate orientation is depicted in the HA maps. While the remote area in the septum showed the characteristic continuous transmural change of HA, the far thinner area of MI did not present this trend as distinctly.

Figure 2 shows the time evolution of native T1, ECV, T2, MD and FA. No significant differences were found between control group and the remote region in the MI group for native T1, ECV, T2, MD and FA. Native T1, $\mathrm{ECV}$ and $\mathrm{MD}$ were significantly elevated in the infarcted region and FA was significantly reduced (Additional file 1: Table S1) with respect to the remote region and control group. During the transition from acute to chronic MI stage, native T1 within the infarcted area remained in a range of 1099-1128 ms (change $<3 \%$ from acute to chronic). On the contrary, ECV as well as MD increased from the acute to the chronic stage by $14 \%$ (ECV), $14 \%$ (MD) and FA decreased by $11 \%$. T2 as a marker for myocardial edema was significantly increased in the ischemic area only during the acute MI stage $(81 \pm 2 \mathrm{~ms}$ infarction vs $58 \pm 2 \mathrm{~ms}$ control $\mathrm{p}<0.001$ and $61 \pm 2 \mathrm{~ms}$ in the remote area $\mathrm{p}<0.001)$ and decreased towards baseline values in all but one animal during chronic MI/follow-up studies.

The correlation results of parametric mapping and diffusion parameters for control/remote/infarct over all time points are presented in Fig. 3. MD correlated well with native T1 and ECV $(r=0.83$ and 0.81 respectively with $\mathrm{p}<0.001)$ and less with $\mathrm{T} 2(\mathrm{r}=0.44$ with $\mathrm{p}=0.05)$ in the infarcted region. FA was inversely correlated to native $\mathrm{T} 1 \quad(\mathrm{r}=-0.75$ with $\mathrm{p}<0.001), \mathrm{ECV}(\mathrm{r}=-0.86$ with $\mathrm{p}<0.001)$ and $\mathrm{T} 2(\mathrm{r}=-0.56$ with $\mathrm{p}<0.01)$ in the infarcted zone. There was no correlation of parameters found in the control or remote region. Corresponding correlation analysis pooling all regions and time points

Table 1 Physiological parameters for control/infarct groups: left ventricular (LV) mass, left ventricular ejection fraction (LVEF), LV end diastolic volume (LVEDV), LV end systolic volume (LVESV), stroke volume (SV) and high sensitivity Troponin T

\begin{tabular}{lllll}
\hline Control/infarct & Baseline & Day 6 & Week 5 & Week 9 \\
\hline LV mass (g) & $51 \pm 7 / 43 \pm 2$ & $58 \pm 8 / 51 \pm 9$ & $71 \pm 10 / 62 \pm 11$ & $85 \pm 8 / 77 \pm 12$ \\
LVEF (\%) & $51 \pm 3 / 49 \pm 4$ & $54 \pm 2 / 47 \pm 3^{*}$ & $56 \pm 1 / 43 \pm 7^{*}$ & $54 \pm 2 / 47 \pm 2^{*}$ \\
LVEDV (ml) & $97 \pm 13 / 85 \pm 6$ & $100 \pm 12 / 108 \pm 13$ & $124 \pm 17 / 122 \pm 14$ & $149 \pm 5 / 152 \pm 16$ \\
LVESV $(\mathrm{ml})$ & $48 \pm 6 / 43 \pm 4$ & $49 \pm 7 / 57 \pm 9$ & $54 \pm 9 / 69 \pm 6^{*}$ & $68 \pm 4 / 81 \pm 8^{*}$ \\
SV (ml) & $50 \pm 7 / 42 \pm 5$ & $54 \pm 5 / 51 \pm 4$ & $70 \pm 9 / 53 \pm 13$ & $81 \pm 4 / 71 \pm 10$ \\
hs-Troponin T (ng/l) & $8.0 \pm 2.7 / 9.0 \pm 5.4$ & $9.8 \pm 7.0 / 130.8 \pm 62.6^{*}$ & $4.5 \pm 1.7 / 7.2 \pm 2.7$ & $5.3 \pm 2.3 / 14.0 \pm 11.5$ \\
\hline
\end{tabular}

The asterisk indicates statistical significance $(p<0.05)$ comparing control and infarction 


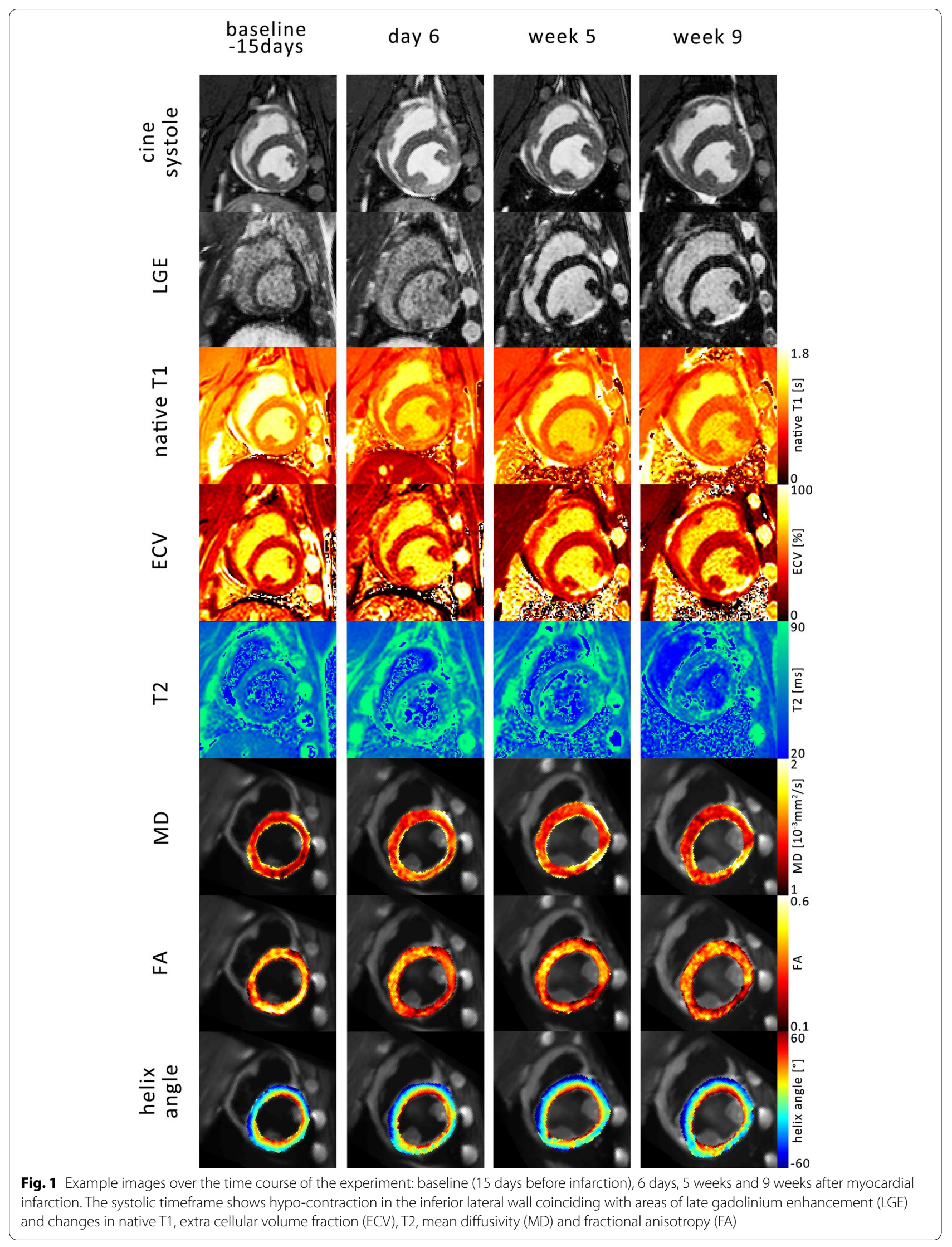



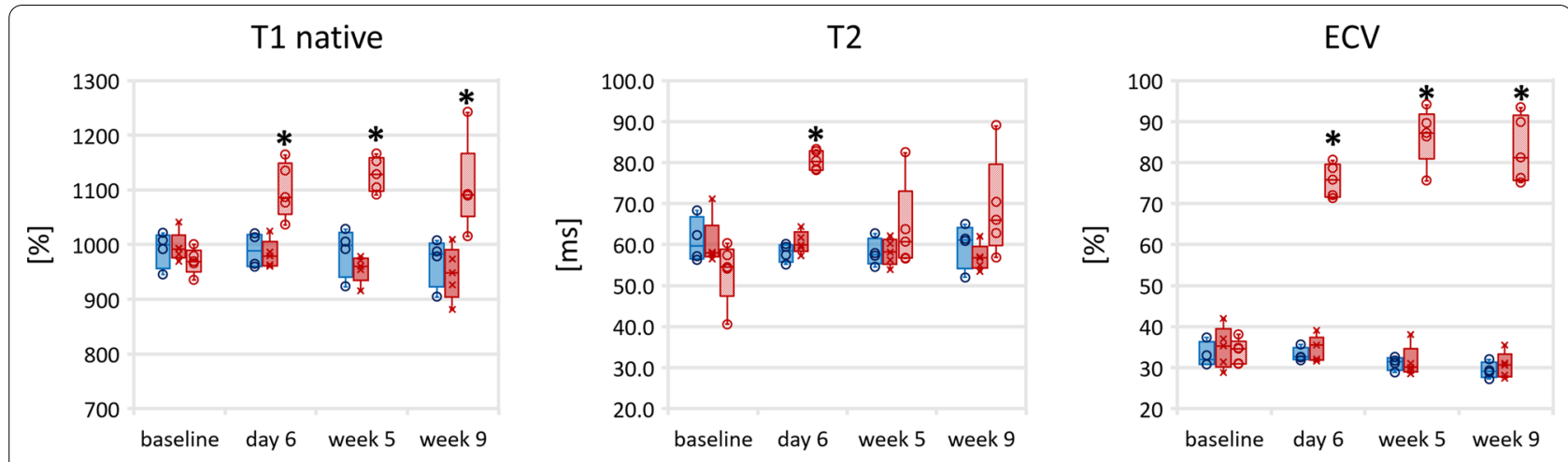

MD

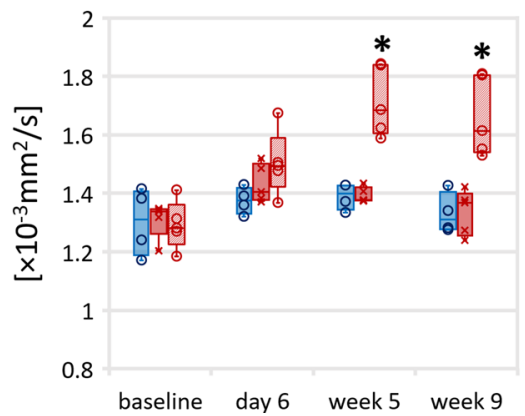

FA

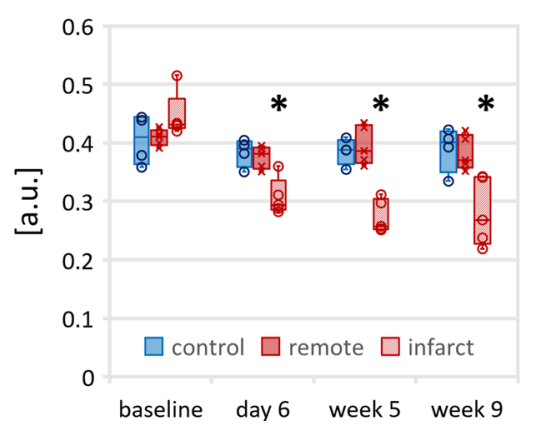

Fig. 2 Progression of relaxivity (native T1, T2, ECV) as well as diffusion parameters (MD, FA) for the control group (blue), the remote area in the infarct group (red) and the infarct area (red shaded). The box corresponds to the center $50 \%$ and the error bars the minimum/maximum. The asterisk indicates statistical significance $(p<0.05)$ comparing to baseline (infarct zone)

as well as scatter plots for individual time points and regions are shown in Additional file 1: Figures S1-S3.

To compare the sensitivity of non-gadoliniumenhanced readouts to gadolinium-enhanced imaging, Fig. 4 shows the results of the relative parameter difference between infarcted and remote areas for native T1, ECV, T2, MD and FA. Correspondingly, the comparison of heathy control data and the remote area of infarcted hearts showed no bias. ECV showed the highest sensitivity with a $174-178 \%$ increase in the infarcted area relative to the remote zone during the chronic stage. Considering non-gadolinium enhanced data, T2 showed the largest relative change between infarct and remote during the acute MI stage $(+33 \pm 4 \%$ day 6 , with $\mathrm{p}=0.013 \mathrm{~T} 2$ vs. $\mathrm{MD}, \mathrm{p}=0.009 \mathrm{~T} 2$ vs. FA and $\mathrm{p}=0.01 \mathrm{~T} 2$ vs. T1) while FA exhibited the largest relative change between infarct and remote during the chronic MI follow-up $(+31 \pm 2 \%$ week 5 , with $\mathrm{p}=$ N.S. FA vs. $\mathrm{MD}, \mathrm{p}=0.03 \mathrm{FA}$ vs. T2 and $\mathrm{p}=0.003 \mathrm{FA}$ vs. T1). Overall, MD as well as FA showed a higher contrast ( $>23 \%$ for $\mathrm{MD}$ and $>27 \%$ for FA) during follow-up compared to native T1 (17-18\%) and T2 (10-20\%). The difference between FA and native T1 was statistically significant for both follow-up time points $(\mathrm{p}<0.01)$ and for MD only for week $9(\mathrm{p}<0.05)$. Similarly, the comparison of FA and T2 reached statistical significance for both follow-up time points $(\mathrm{p}<0.01)$, while $\mathrm{MD}$ was only statistically significantly different for week 5 $(\mathrm{p}<0.05)$. During the acute stage, diffusion and relaxometry parameters were all significantly different from other time points.

The analysis of change of functional and structural parameters such as LVEF, global myocardial strains, torsion and transmural HA gradient is shown in Fig. 5 and the corresponding values are reported in Table 2.

In the control cohort, LVEF, GRS and GCS increased in magnitude from baseline to week 5 (increase by $10 \%$ [ $2 \%$ to $18 \%$ ] EF; $22 \%$ [ $5 \%$ to $69 \%$ ] GRS; $10 \%$ [ $-6 \%$ to $37 \%$ ] GCS) followed by a decrease towards the final time point. This trend is not mirrored in the MI group as LVEF drops $(-14 \%$ [ $+3 \%$ to $-37 \%]$ week 5$)$.

The transmural HA gradient remained constant from day 6 until the end in the control group, but continued to become steeper in the MI group until week 5 (9\% increase from day 6 to week 5). From week 5 to 9 there was no change found in the MI group.

The corresponding correlation plots are shown in Fig. 6. While radial strain and torsion (Fig. 5) showed changes during disease progression, no significant 

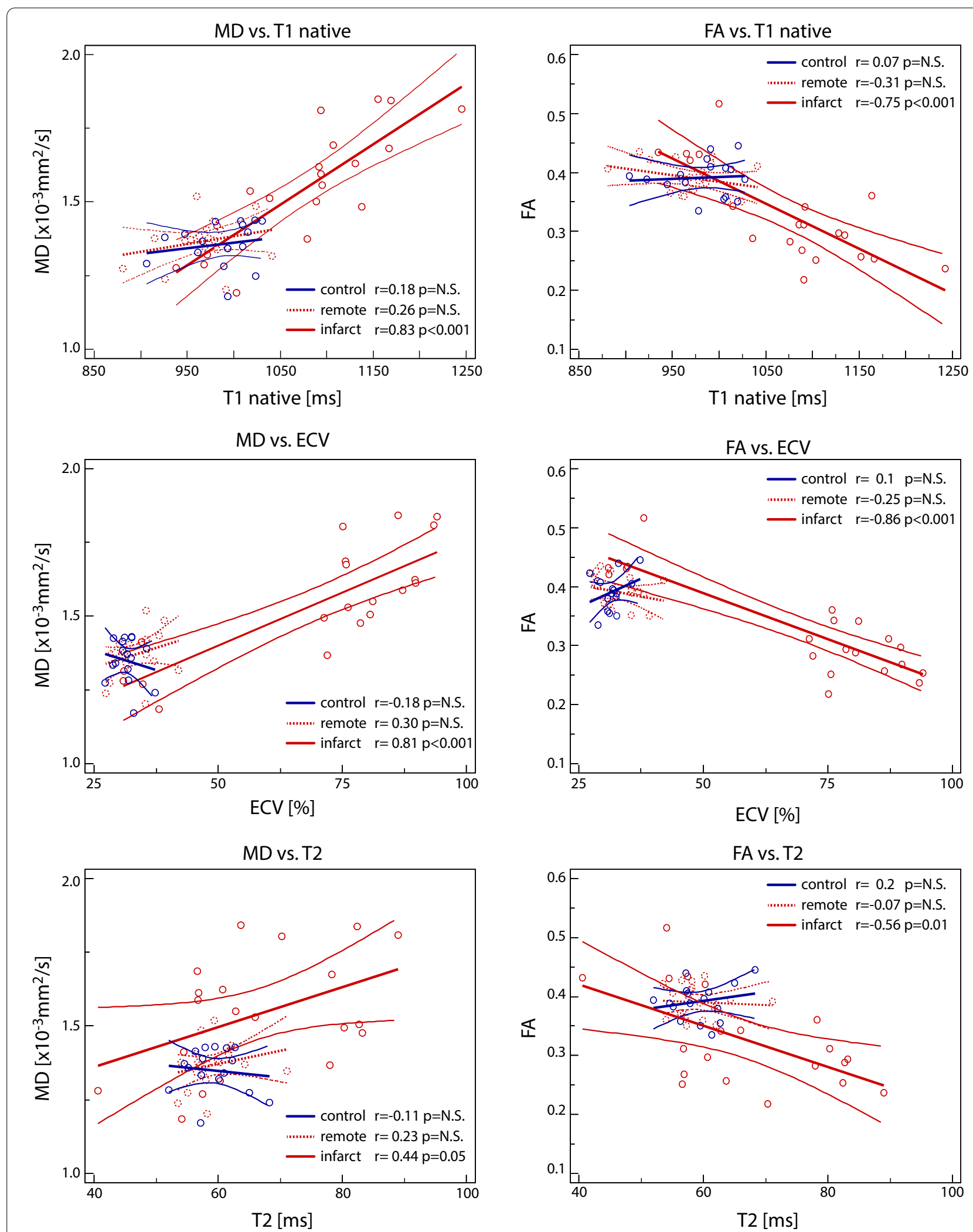

Fig. 3 Correlation plots of relaxometry (native T1, ECV, T2) vs. diffusion parameters (MD, FA) over all time points. The blue lines indicate the control group, the red dotted lines the remote area in the infarct group and the red straight lines the infarcted area. Linear regression is plotted including the $95 \%$ confidence interval 


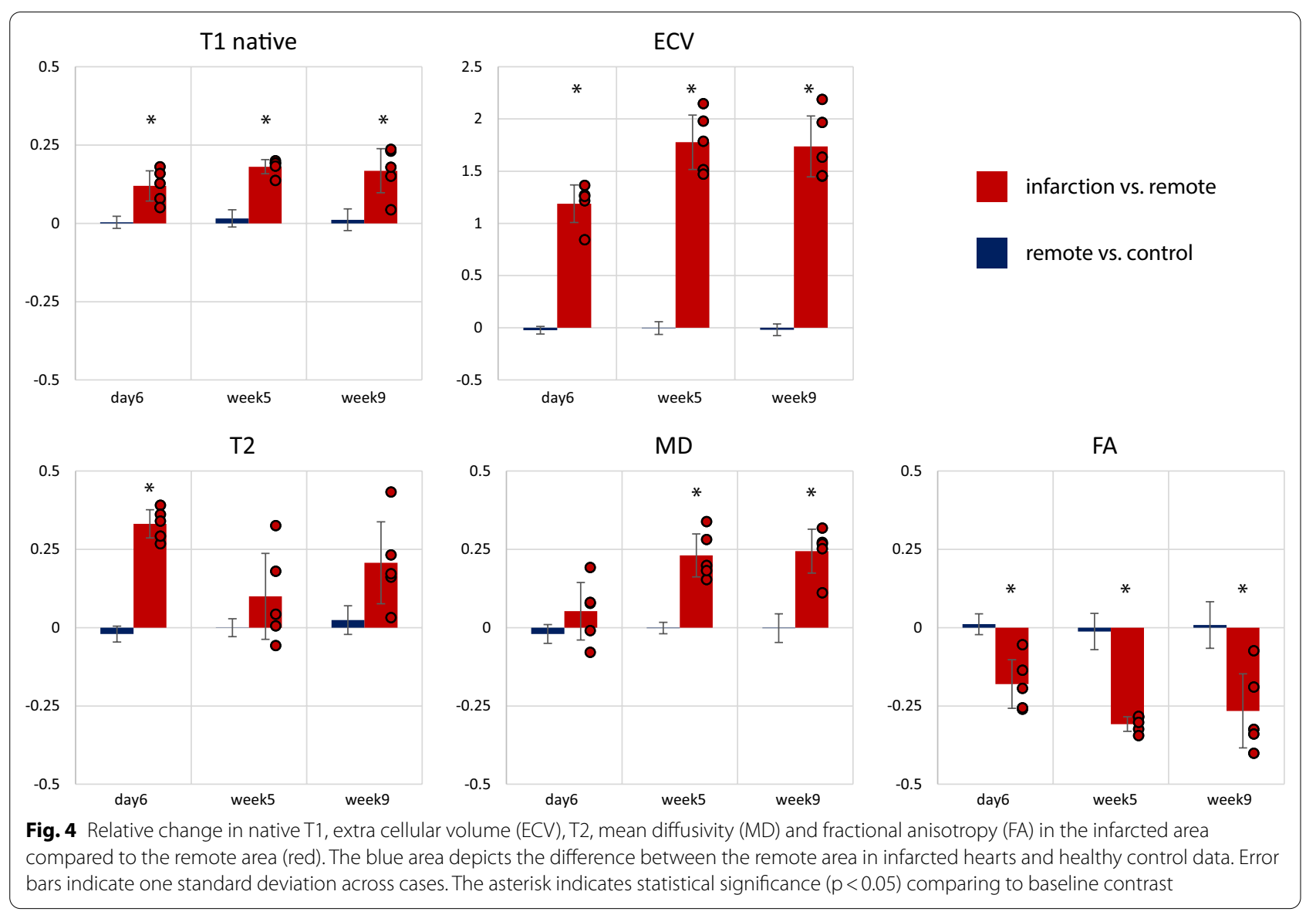

correlation was found with the transmural HA gradient in the remote zone. However, a significant correlation between longitudinal strain and transmural HA gradient was detected $(\mathrm{r}=0.59$ with $\mathrm{p}<0.05)$.

Correlation with relative scar mass showed a fair correlation with longitudinal strain $(R=0.48 \mathrm{p}<0.032)$ and good correlation with transmural HA variation $(R=0.71$ $\mathrm{p}<0.001)$.

\section{Discussion}

In this study, we observed functional and structural changes after experimental MI. Edema during the acute MI stage was captured by elevated T2 values, while elevated native T1, ECV, MD and reduced FA values were found in the infarcted region during chronic MI followup. A reduction of ventricular torsion as well as longitudinal strain was present during the chronic stage together with a trend towards a steeper transmural HA distribution in the remote area.

Upon ischemia, a bimodal occurrence of edema has been reported in swine and humans $[6,41]$. The deferred edema peaking at approximately 1 week post-MI has been attributed to healing processes accompanied by elevated T2 values in the ischemic region [42]. We found elevated T2 values during the acute stage (day 6) that converged back to baseline values during the chronic stage, in line with previous work [6]. The presence of edema during the acute stage coincided with an increase in MD and a decrease in FA. The increase in MD and reduction in FA in the ischemic region are attributed to the increase of ECV due to edema. Interestingly, FA and ECV exhibited a larger change in magnitude from baseline to acute stage, compared to the transition of acute to chronic stage, while the change in MD was larger in the chronic stage. Consequently, a higher correlation between ECV and FA was found compared to ECV and $M D$. The finding suggests that MD is more sensitive to chronic changes during scar formation, rather than to acute tissue swelling. During the acute MI stage, T2 mapping showed the largest difference between infarcted and remote regions emphasizing its value in identifying edema.

The chronic MI stage was reached by week 5 with absence of edema as T2 values normalized close to baseline values. ECV, MD and FA significantly increased in week 5 with a reduction of MD and ECV in week 9, as 


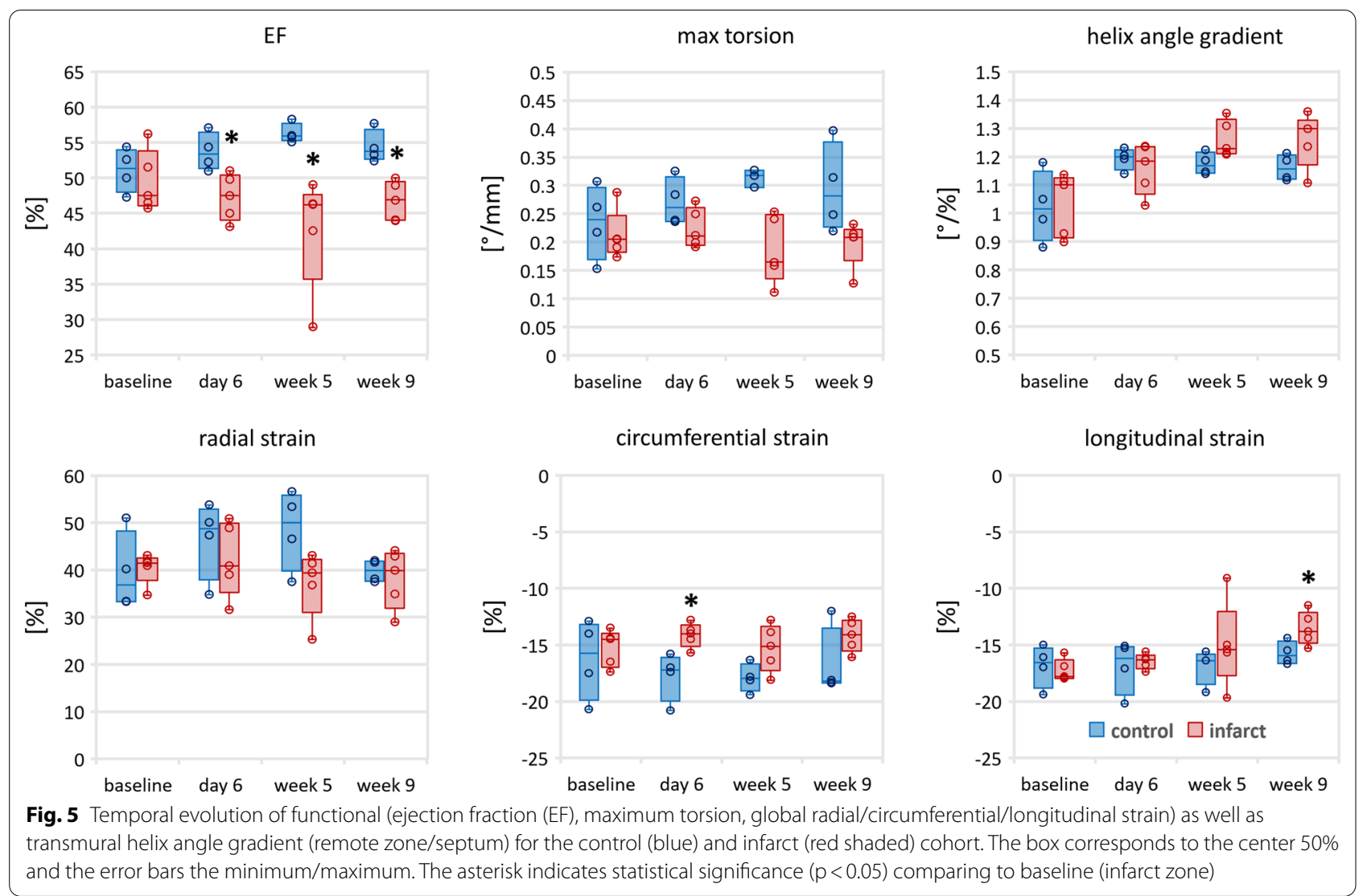

Table 2 Global radial, circumferential and longitudinal strains as well as torsion of the LV and transmural helix angle gradients of the remote (septal) region

\begin{tabular}{llllll}
\hline & $\begin{array}{l}\text { Global radial strain } \\
(\%)\end{array}$ & $\begin{array}{l}\text { Global circumferential } \\
\text { strain (\%) }\end{array}$ & $\begin{array}{l}\text { Global longitudinal } \\
\text { strain (\%) }\end{array}$ & $\begin{array}{l}\text { Torsion (\%/mm) } \\
\text { Helix angle } \\
\text { gradient }(\% \%)\end{array}$ & $\begin{array}{l} \\
\text { Control animal }\end{array}$ \\
Baseline & $39 \pm 7$ & & $-17 \pm 1$ & $0.23 \pm 0.05$ & $-1.02 \pm 0.11$ \\
Day 6 & $47 \pm 7$ & $-16 \pm 3$ & $-17 \pm 2$ & $0.26 \pm 0.03$ & $-1.19 \pm 0.03$ \\
Week 5 & $49 \pm 7$ & $-18 \pm 2$ & $-17 \pm 1$ & $0.31 \pm 0.03$ & $-1.17 \pm 0.03$ \\
Week 9 & $40 \pm 2$ & $-18 \pm 1$ & $-16 \pm 1$ & $0.28 \pm 0.05$ & $-1.16 \pm 0.04$ \\
Infarct animal & & $-17 \pm 3$ & & & $-1.04 \pm 0.10$ \\
Baseline & $40 \pm 3$ & $-15 \pm 1$ & $-17 \pm 1$ & $0.20 \pm 0.03$ & $-1.16 \pm 0.08$ \\
Day 6 & $42 \pm 7$ & $-14 \pm 1$ & $-16 \pm 1$ & $0.23 \pm 0.05$ & $-1.26 \pm 0.06$ \\
Week 5 & $37 \pm 6$ & $-15 \pm 2$ & $-15 \pm 3$ & $0.20 \pm 0.06$ & $-1.26 \pm 0.08$ \\
Week 9 & $38 \pm 6$ & $-14 \pm 1$ & $-14 \pm 1$ & $0.21 \pm 0.02$ & \\
\hline
\end{tabular}

well as a significant decrease in FA corresponding to scar formation. Increased values of MD and decreased values of FA within scarred regions have previously been reported in in-vivo [43, 44] and ex-vivo [45] cDTI. While swelling of the interstitium and cardiomyocytes during the acute stage leads to a longer free path for water diffusion, full disintegration of cell membranes in the scarred region leads to fewer diffusion restrictions and structural disorder reflected in elevated MD and reduced FA values. Interestingly, diffusional parameters showed a larger relative change during chronic follow-up compared to both non-contrast methods: native T1 and T2 mapping. The underlying change in tissue properties due to scar formation was identical for both parametric mapping and cDTI. However, imaging physics differ. While native T1 

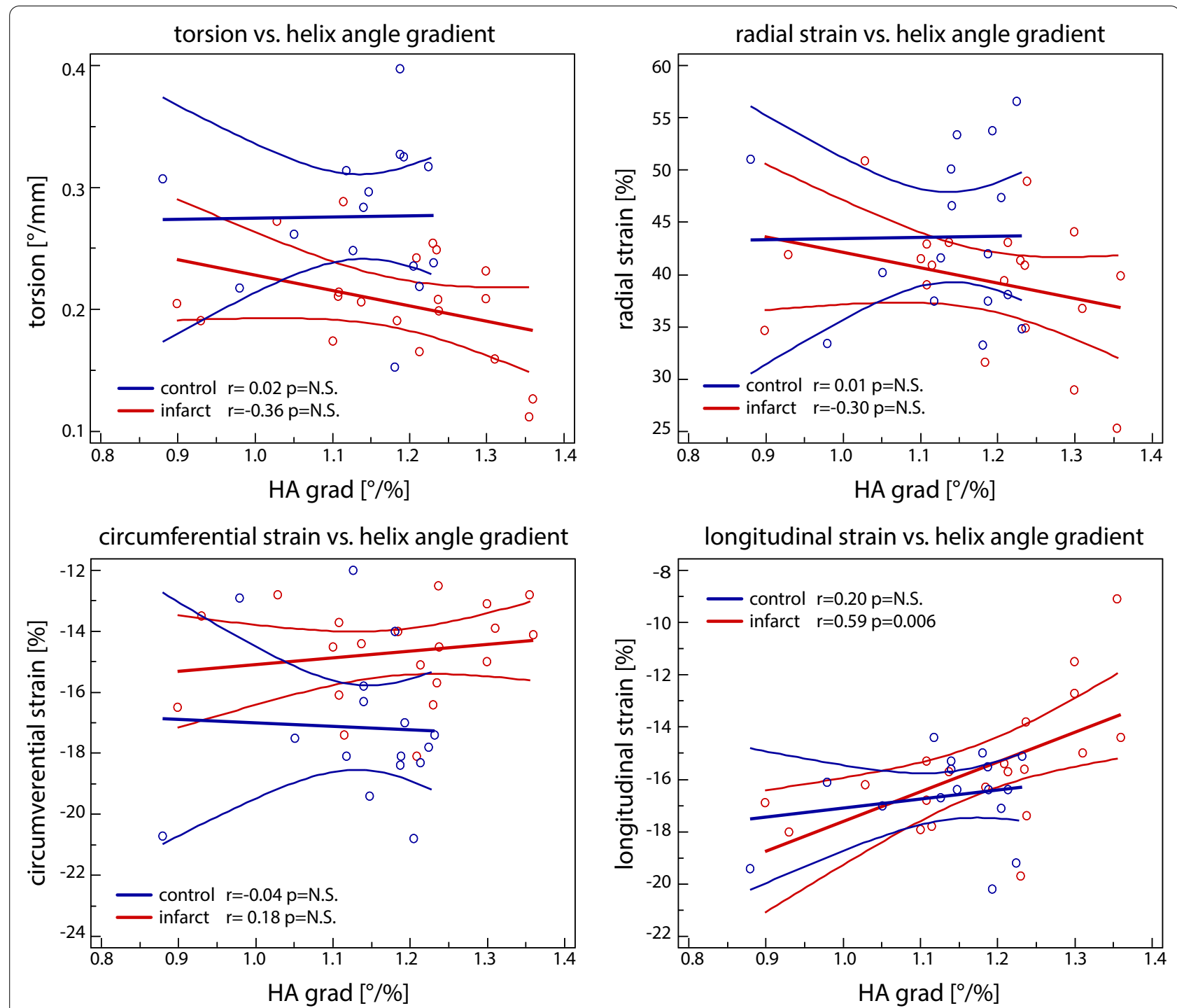

Fig. 6 Correlation of torsion and strains with remote (septal) transmural helix angle gradient (HA grad) for the control (blue) and the infarcted (red) group

and T2 imaging probe changes in spin-lattice and spinspin interaction, MD reflects changes in viscosity of the imaged liquid as well as the mean free pathway water molecules can diffuse without restriction as imposed by semipermeable and non-permeable membranes. Correspondingly, FA is predominantly probing changes in diffusion measurements as a function of spatial orientation and hence the overall anisotropy of tissue architecture. Our results suggest a significantly higher sensitivity to changes in myocardial microstructure by cDTI. However, if contrast agents were used, ECV presented the most prominent changes in contrast favouring contrast agentbased imaging over native-contrast diffusion imaging and relaxometry mapping.
In this study, the the LCX was occluded leading to an infarction area within the lateral wall of the LV. The septum was consequently chosen as remote zone.

Up to week 5, an increase of LVEF, torsion as well as radial strain was found in the control cohort that may be attributed to animal growth. In the control group, the transmural HA gradient only increased within the first 21 days (baseline to day 6), remained unchanged for the remainder of the experiment. In the MI group, this trend was not seen, as LVEF decreased immediately after induction of MI reflecting acute loss of function. The acute changes in function were followed by structural remodelling in the remote zone during chronic follow-up up to week 5 . With structural remodelling, torsion, radial as well as longitudinal strain reduced in magnitude. The 
correlation analysis suggests a link between the structural changes in the remote zone and the loss of longitudinal strain. A reduction in LGS has been shown to correlate with poor outcome [46, 47] and LV remodelling [48].

Biomechanical modelling that was performed as part of a study on patients suffering from dilated cardiomyopathy revealed an increase in GLS associated with a steeper HA [49]. To this end, the trend towards elevated transmural HA variation may reflect a compensatory mechanism to address the lack of long-axis shortening in the presence of non-contractile infarcted tissue. During the early chronic follow up (week 5), GLS was comparable to the control cohort despite the presence of MI and an elevated HA was found. The increase in transmural HA, however discontinued after week 5 coinciding with a reduction of longitudinal strain potentially indicating onset of heart failure.

In a previous study on the comparison of LAD and LCX occlusion in swine with 1 and 3 months follow-up, a reduction in LVEF, GRS, GCS, GLS as well as torsion has been reported, when compared to a control group [50]. In line with our study, the authors did not find a correlation of radial/circumferential strain with clinical parameters such as LVEF, LVESV and scar size, while they found moderate correlation of these parameters with torsion and strong correlation with GLS.

\section{Limitations}

While trends in changes of functional as well as structural parameters have been found, the study cohort is too small to conclude on statistical significance on some of the trends.

Control animals did not undergo a sham procedure.

Occlusion of the LCX was chosen as it was deemed to be tolerated better by the animals and lead to fewer dropouts. However, the affected area was located in the lateral wall between the papillary muscles. Both papillary muscles tend to stabilize the wall during contraction, potentially reducing the overall burden to the heart, when compared to large anterior wall infarctions. This may also be a reason why no significant changes in LV shape were observed.

A dependency of LV rotation [19], ventricular shape remodelling and dysfunction [51] on the location of MI has been reported. This indicates a potential dependency of myocardial response to the site of coronary occlusion and hence different microstructural remodelling.

While histology has been the standard method for validation of $\mathrm{cDTI}$, more recently high resolution synchrotron imaging of entire rat hearts has been used to confirm the microstructural findings [52]. Neither methods have been available for this study. One key limiting factor compared to such ex-vivo measurements is the limited spatial resolution of in-vivo imaging.

Furthermore, CMR imaging had to be performed in different heart phases due to sequence requirements (e.g. DTI in systole and T2 mapping in diastole). The use of different imaging readouts (e.g. single shot EPI vs. multi shot gradient/spin echo) resulted in different off-resonance related image artefacts, causing geometrical and intensity distortions predominantly in the vicinity of the posterior vein [53]. This required manual segmentation of regions of interest according to anatomical landmarks and may add to additional variation.

\section{Conclusion}

We longitudinally assessed the dynamics of MI from the acute to the chronic stage by functional and microstructural CMR imaging. Considering non-contrast enhanced methods, differentiation of infarcted and remote tissue based on diffusion parameters was superior when compared to native T1 and T2 mapping in the chronic stage, indicating a higher sensitivity of cDTI compared to relaxometry in response to microstructural alterations. Moreover, the correlation between microstructural changes and reduced global contraction and rotation illustrates the multi-scale response of the heart to myofiber injury and scar formation. Therefore, the combination of functional and microstructural diffusion-based CMR imaging is considered a valuable tool to characterize MI across spatial scales.

\section{Abbreviations}

BW: Body weight; CDTI: Cardiac diffusion tensor imaging; CMR: Cardiovascular magnetic resonance; CSPAMM: Complementary spatial modulation of magnetization; ECG: Electrocardiogram; ECV: Extracellular volume fraction; EPI: Echo planar imaging; FA: Fractional anisotropy; GCS: Global circumferential strain; GLS: Global longitudinal strain; GRS: Global radial strain; HA: Helical angle; hsTNT: High sensitivity troponin T; LAD: Left anterior descending coronary artery; LCX: Left circumflex coronary artery; LGE: Late gadolinium enhancement; LV: Left ventricle/left ventricular; LVEDV: Left ventricular enddiastolic volume; LVEF: Left ventricular ejection fraction; LVESV: Left ventricular end-systolic volume; MACE: Major adverse cardiac events; MD: Mean diffusivity; MI: Myocardial infarction; MOLLI: Modified Look-Locker inversion recovery; SV: Stroke volume; TE: Echo time; TR: Repetition time.

\section{Supplementary Information}

The online version contains supplementary material available at https://doi. org/10.1186/s12968-021-00794-5.

Additional file 1: Table S1. Native T1, T2, extra cellular volume (ECV), mean diffusivity (MD) and fractional anisotropy (FA) for healthy controls and for the remote as well as infarcted zone of the infarct cohort. The asterisk indicates statistically significant differences between infarcted and remote regions ( $<<0.05)$. Fig. S1. Pearson correlation of all time points and all regions (control/remote/infarction). The asterisk indicates a $p$-value $<0.001$. ECV, extracellular volume fraction; MD, mean diffusivity, FA, fractional anisotropy. Fig. S2. Scatter plots plotting mean diffusivity (MD) against extra cellular volume (ECV), T1 native and T2 for each region (control/remote/infarct) and each time point individually. Fig. S3. Scatter 
plots of fractional anisotropy (FA) against extra cellular volume (ECV), native $\mathrm{T} 1$ and $\mathrm{T} 2$ for each region (control/remote/infarct) and for each time point individually.

\section{Acknowledgements}

Not applicable.

\section{Authors' contributions}

CTS: study coordination, study design, CMR sequence and image reconstruction programming, in-vivo measurements, post-processing, data analysis, manuscript preparation, preparation and monitoring of animals, ethics approval. CVD, MF, RVG: in-vivo measurements, CMR sequence and image reconstruction programming, post-processing, data analysis. MP, CW: postprocessing, data analysis. MK, TF, NC, MW: study design, study coordination, preparation and monitoring of animals, ethics approval. SK: study coordination, study design. All authors read and approved the final manuscript.

\section{Funding}

This research was funded by the Swiss National Science Foundation, Grants SNF PZOOP2 174144 320030_153014 and CR23I3_166485.

\section{Availability of data and materials}

Upon reasonable request to the corresponding author.

\section{Declarations}

\section{Ethics approval and consent to participate}

Animal handling, procedures and protocols were approved by the Cantonal Veterinary Office (Zurich, Switzerland) under license ZH072/16. Housing and experimental procedures were in accordance with the Swiss Animal Protection Law and Ordinance and were also conform to the European Directive 2010/63/EU of the European Parliament and of the Council of 22 September 2010 on the Protection of Animals Used for Scientific Purposes and to the Guide for the Care and Use of Laboratory Animals.

\section{Consent for publication}

Not applicable.

\section{Competing interests}

The authors declare that they have no competing interests.

\section{Author details}

${ }^{1}$ Institute for Biomedical Engineering, University and ETH Zurich, Gloriastrasse 35, 8092 Zurich, Switzerland. ${ }^{2}$ Institute of Diagnostic and Interventional Radiology, University Hospital Zurich, Zurich, Switzerland. ${ }^{3}$ Division of Surgical Research, University Hospital Zurich, Zurich, Switzerland. ${ }^{4}$ Institute of Translational Cardiovascular Technologies, ETH Zurich, Zurich, Switzerland.

Received: 6 January 2021 Accepted: 9 July 2021

Published online: 20 September 2021

\section{References}

1. Kostuk WJ, Kazamias TM, Gander MP, Simon AL, Ross J. Left ventricular size after acute myocardial infarction. Serial changes and their prognostic significance. Circulation. 1973;47:1174-9. https://doi.org/10.1161/01.CIR. 47.6.1174.

2. Pfeffer MA, Braunwald E. Ventricular remodeling after myocardial infarction. Experimental observations and clinical implications. Circulation. 1990;81:1161-72. https://doi.org/10.1161/01.CIR.81.4.1161.

3. Abbate A, Bussani R, Amin MS, Vetrovec GW, Baldi A. Acute myocardial infarction and heart failure: role of apoptosis. Int J Biochem Cell Biol. 2006;38:1834-40. https://doi.org/10.1016/j.biocel.2006.04.010.

4. Gaudron P, Eilles C, Kugler I, Ertl G. Progressive left ventricular dysfunction and remodeling after myocardial infarction potential mechanisms and early predictors. Circulation. 1994;89:1905. https://doi.org/10.1161/circ. 89.4.8149558
5. Ibanez B, Aletras AH, Arai AE, et al. Cardiac MRI endpoints in myocardial infarction experimental and clinical trials: JACC Scientific Expert Panel. J Am Coll Cardiol. 2019;74:238-56. https://doi.org/10.1016/j.jacc.2019.05. 024.

6. Fernández-Jiménez R, Sánchez-González J, Agüero J, et al. Myocardial edema after ischemia/reperfusion is not stable and follows a bimodal pattern: imaging and histological tissue characterization. J Am Coll Cardiol. 2015;65:315-23. https://doi.org/10.1016/j.jacc.2014.11.004.

7. Moon JC, Messroghli DR, Kellman P, et al. Myocardial T1 mapping and extracellular volume quantification: a Society for Cardiovascular Magnetic Resonance (SCMR) and CMR Working Group of the European Society of Cardiology consensus statement. J Cardiovasc Magn Reson. 2013;15:92. https://doi.org/10.1186/1532-429X-15-92.

8. Viallon M, Jacquier A, Rotaru C, Delattre BMA, Mewton N, Vincent F, Croisille P. Head-to-head comparison of eight late gadolinium-enhanced cardiac MR (LGE CMR) sequences at 1.5 tesla: from bench to bedside. J Magn Reson Imaging. 2011;34:1374-87. https://doi.org/10.1002/jmri. 22783

9. Swynghedauw B. Molecular mechanisms of myocardial remodeling. Physiol Rev. 1999;79:215-62. https://doi.org/10.1152/physrev.1999.79.1. 215.

10. Olivetti G, Quaini F, Lagrasta C, Cigola E, Ricci R, Maestri R, Anversa P. Cellular basis of ventricular remodeling after myocardial infarction in rats. Cardioscience. 1995:6:101-6.

11. Grossman W, Jones D, McLaurin LP. Wall stress and patterns of hypertrophy in the human left ventricle. J Clin Invest. 1975;56:56-64. https://doi. org/10.1172/JCl108079.

12. McKay RG, Pfeffer MA, Pasternak RC, Markis JE, Come PC, Nakao S, Alderman JD, Ferguson JJ, Safian RD, Grossman W. Left ventricular remodeling after myocardial infarction: a corollary to infarct expansion. Circulation. 1986:74:693-702. https://doi.org/10.1161/01.CIR.74.4.693.

13. Lamas GA, Vaughan DE, Parisi AF, Pfeffer MA. Effects of left ventricular shape and captopril therapy on exercise capacity after anterior wall acute myocardial infarction. Am J Cardiol. 1989;63:1167-73.

14. White HD, Norris RM, Brown MA, Brandt PW, Whitlock RM, Wild CJ. Left ventricular end-systolic volume as the major determinant of survival after recovery from myocardial infarction. Circulation. 1987;76:44-51. https:// doi.org/10.1161/01.CIR.76.1.44.

15. Yang L, Cao S, Liu W, Wang T, Xu H, Gao C, Zhang L, Wang K. Cardiac magnetic resonance feature tracking: a novel method to assess left ventricular three-dimensional strain mechanics after chronic myocardial infarction. Acad Radiol. 2020. https://doi.org/10.1016/j.acra.2020.03.013.

16. Reindl $M$, Tiller $C$, Holzknecht $M$, et al. Prognostic implications of global longitudinal strain by feature-tracking cardiac magnetic resonance in ST-elevation myocardial infarction. Circ Cardiovasc Imaging. 2019:12:e009404.

17. Huttin O, Coiro S, Selton-Suty C, Juillière Y, Donal E, Magne J, Sadoul N, Zannad F, Rossignol P, Girerd N. Prediction of left ventricular remodeling after a myocardial infarction: role of myocardial deformation: a systematic review and meta-analysis. PLoS ONE. 2016;11:1-14. https://doi.org/10. 1371/journal.pone.0168349.

18. Abate E, Hoogslag GE, Leong DP, et al. Association between multilayer left ventricular rotational mechanics and the development of left ventricular remodeling after acute myocardial infarction. J Am Soc Echocardiogr. 2014;27:239-48. https://doi.org/10.1016/j.echo.2013.12.009.

19. Park SM, Hong SJ, Ahn CM, Kim YH, Kim JS, Park JH, Lim DS, Shim WJ. Different impacts of acute myocardial infarction on left ventricular apical and basal rotation. Eur Heart J Cardiovasc Imaging. 2012;13:483-9. https://doi.org/10.1093/ejechocard/jer272.

20. Schelbert EB, Testa SM, Meier CG, et al. Myocardial extravascular extracellular volume fraction measurement by gadolinium cardiovascular magnetic resonance in humans: slow infusion versus bolus. J Cardiovasc Magn Reson. 2011;13:1-14. https://doi.org/10.1186/1532-429X-13-16.

21. Wang Y, Cai W, Wang L, Xia R. Evaluate the early changes of myocardial fibers in rhesus monkey during sub-acute stage of myocardial infarction using diffusion tensor magnetic resonance imaging. Magn Reson Imaging. 2016;34:391-6. https://doi.org/10.1016/j.mri.2015.12.007.

22. Wu Y, Chan CW, Nicholls JM, Liao S, Tse HF, Wu EX. MR study of the effect of infarct size and location on left ventricular functional and microstructural alterations in porcine models. J Magn Reson Imaging. 2009;29:30512. https://doi.org/10.1002/jmri.21598. 
23. Kung GL, Vaseghi M, Gahm JK, Shevtsov J, Garfinkel A, Shivkumar K, Ennis DB. Microstructural infarct border zone remodeling in the post-infarct swine heart measured by diffusion tensor MRI. Front Physiol. 2018;9:1-9. https://doi.org/10.3389/fphys.2018.00826.

24. Walker JC, Guccione JM, Jiang Y, Zhang P, Wallace AW, Hsu EW, Ratcliffe MB. Helical myofiber orientation after myocardial infarction and left ventricular surgical restoration in sheep. J Thorac Cardiovasc Surg. 2005;129:382-90. https://doi.org/10.1016/j.jtcvs.2004.06.006.

25. Wu M-T, Su M-YM, Huang Y-L, Chiou K-R, Yang P, Pan H-B, Reese TG, Wedeen VJ, Tseng W-YI. Sequential changes of myocardial microstructure in patients postmyocardial infarction by diffusion-tensor cardiac MR: correlation with left ventricular structure and function. Circ Cardiovasc Imaging. 2009;2:32-40, 6 p following 40. https://doi.org/10.1161/CIRCI MAGING.108.778902.

26. Mekkaoui C, Jackowski MPMP, Kostis WJWJ, Stoeck CTCT, Thiagalingam A, Reese TGTG, Reddy VYVY, Ruskin JNJN, Kozerke S, Sosnovik DEDE. Myocardial scar delineation using diffusion tensor magnetic resonance tractography. J Am Heart Assoc. 2018;7:1-11. https://doi.org/10.1161/ JAHA.117.007834.

27. Rutz AK, Ryf S, Plein S, Boesiger P, Kozerke S. Accelerated whole-heart 3D CSPAMM for myocardial motion quantification. Magn Reson Med. 2008;59:755-63. https://doi.org/10.1002/mrm.21363.

28. Fischer SE, McKinnon GC, Maier SE, Boesiger P. Improved myocardial tagging contrast. Magn Reson Med. 1993;30:191-200.

29. Wang H, Stoeck CT, Kozerke S, Amini AAA. Analysis of 3D cardiac deformations with 3D SinMod. IEEE EMBS. 2013;2013:4386-9. https://doi.org/ 10.1109/EMBC.2013.6610518.

30. Young AA, Cowan BR. Evaluation of left ventricular torsion by cardiovascular magnetic resonance. J Cardiovasc Magn Reson. 2012;14:49. https:// doi.org/10.1186/1532-429X-14-49.

31. Messroghli DR, Radjenovic A, Kozerke S, Higgins DM, Sivananthan MU, Ridgway JP. Modified look-locker inversion recovery (MOLLI) for highresolution T 1 mapping of the heart. Magn Reson Med. 2004;52:141-6. https://doi.org/10.1002/mrm.20110.

32. Fernández-Jiménez R, Sánchez-González J, Aguero J, del Trigo M, Galán-Arriola C, Fuster V, Ibáñez B. Fast T2 gradient-spin-echo (T2-GraSE) mapping for myocardial edema quantification: first in vivo validation in a porcine model of ischemia/reperfusion. J Cardiovasc Magn Reson. 2015;17:92. https://doi.org/10.1186/s12968-015-0199-9.

33. Gotschy A, von Deuster C, Stoeck CT., et al. Myocardial extracellular volume expansion precedes functional myocardial alterations during the evolution of systemic sclerosis. In: Proc Intl Soc Mag Reson Med. 2017; 25.

34. Welsh C, Di Bella E, Hsu E. Higher-order motion-compensation for in vivo cardiac diffusion tensor imaging in rats. IEEE Trans Med Imaging. 2015;0062:1-1. https://doi.org/10.1109/TMI.2015.2411571.

35. Stoeck CT, von Deuster C, Genet M, Atkinson D, Kozerke S. Second-order motion-compensated spin echo diffusion tensor imaging of the human heart. Magn Reson Med. 2015. https://doi.org/10.1002/mrm.25784.

36. Gotschy A, Von Deuster C, Van Gorkum RJH, Gastl M, Vintschger E, Schwotzer R, Flammer AJ, Manka R, Stoeck CT, Kozerke S. Characterizing cardiac involvement in amyloidosis using cardiovascular magnetic resonance diffusion tensor imaging. J Cardiovasc Magn Reson. 2019;21:1-9. https://doi.org/10.1186/s12968-019-0563-2.

37. Stoeck CT, von Deuster C, Fleischmann T, Lipiski M, Cesarovic N, Kozerke S. Direct comparison of in vivo versus postmortem second-order motioncompensated cardiac diffusion tensor imaging. Magn Reson Med. 2017. https://doi.org/10.1002/mrm.26871.

38. Wilm BJ, Gamper U, Henning A, Pruessmann KP, Kollias SS, Boesiger P. Diffusion-weighted imaging of the entire spinal cord. NMR Biomed. 2009;22:174-81. https://doi.org/10.1002/nbm.1298.

39. Cerqueira MD. Standardized myocardial segmentation and nomenclature for tomographic imaging of the heart: a statement for healthcare professionals from the Cardiac Imaging Committee of the Council on Clinical Cardiology of the American Heart Association. Circulation. 2002;105:53942. https://doi.org/10.1161/hc0402.102975.

40. Ferreira PF, Nielles-Vallespin S, Scott AD, Khalique Z, Pennell DJ, Firmin DN Dual identity of the interventricular septum with in vivo diffusion tensor imaging. In: Proceedings of the 26th ISMRM. 2017. p. 2764.
41. Fernández-Jiménez R, Barreiro-Pérez M, Martin-García A, et al. Dynamic edematous response of the human heart to myocardial infarction: implications for assessing myocardial area at risk and salvage. Circulation. 2017;136:1288-300. https://doi.org/10.1161/CIRCULATIONAHA.116. 025582.

42. Fernández-Jiménez R, García-Prieto J, Sánchez-González J, Agüero J, López-Martín GJ, Galán-Arriola C, Molina-Iracheta A, Doohan R, Fuster V, Ibáñez B. Pathophysiology underlying the bimodal edema phenomenon after myocardial ischemia/reperfusion. J Am Coll Cardiol. 2015;66:816-28. https://doi.org/10.1016/j.jacc.2015.06.023.

43. Mekkaoui C, Jackowski MP, Kostis WJ, Stoeck CT, Thiagalingam A, Reese TG, Reddy VY, Ruskin JN, Kozerke S, Sosnovik DE. Myocardial scar delineation using diffusion tensor magnetic resonance tractography. J Am Heart Assoc. 2018;7:e007834. https://doi.org/10.1161/JAHA.117.007834.

44. Wu MT, Tseng WYI, Su MYM, Liu CP, Chiou KR, Wedeen VJ, Reese TG, Yang CF. Diffusion tensor magnetic resonance imaging mapping the fiber architecture remodeling in human myocardium after infarction: correlation with viability and wall motion. Circulation. 2006;114:1036-45. https:// doi.org/10.1161/CIRCULATIONAHA.105.545863.

45. Winklhofer S, Stoeck CT, Berger N, Thali M, Manka R, Kozerke S, Alkadhi H, Stolzmann P. Post-mortem cardiac diffusion tensor imaging: detection of myocardial infarction and remodeling of myofiber architecture. Eur Radiol. 2014. https://doi.org/10.1007/s00330-014-3322-7.

46. Bertini M, Ng ACT, Antoni ML, Nucifora G, Ewe SH, Auger D, Marsan NA, Schalij MJ, Bax JJ, Delgado V. Global longitudinal strain predicts long-term survival in patients with chronic ischemic cardiomyopathy. Circ Cardiovasc Imaging. 2012;5:383-91. https://doi.org/10.1161/CIRCIMAGING.111. 970434.

47. Cho GY, Marwick TH, Kim HS, Kim MK, Hong KS, Oh DJ. Global 2-dimensional strain as a new prognosticator in patients with heart failure. J Am Coll Cardiol. 2009:54:618-24. https://doi.org/10.1016/j.jacc.2009.04.061.

48. Zaliaduonyte-Peksiene D, Vaskelyte JJ, Mizariene V, Jurkevicius R, Zaliunas R. Does longitudinal strain predict left ventricular remodeling after myocardial infarction? Echocardiography. 2012;29:419-27. https://doi.org/10. 1111/j.1540-8175.2011.01597.x.

49. Von Deuster C, Sammut E, Asner L, Nordsletten D, Lamata P, Stoeck CT, Kozerke S, Razavi R. Studying dynamic myofiber aggregate reorientation in dilated cardiomyopathy using in vivo magnetic resonance diffusion tensor imaging. Circ Cardiovasc Imaging. 2016;9:e005018. https://doi.org/ 10.1161/CIRCIMAGING.116.005018.

50. Ishikawa K, Aguero J, Tilemann L, Ladage D, Hammoudi N, Kawase Y, Santos-Gallego CG, Fish K, Levine RA, Hajjar RJ. Characterizing preclinical models of ischemic heart failure: differences between LAD and LCX infarctions. AJP Hear Circ Physiol. 2014;307:H1478-86. https://doi.org/10. 1152/ajpheart.00797.2013.

51. Masci PG, Ganame J, Francone M, et al. Relationship between location and size of myocardial infarction and their reciprocal influences on post-infarction left ventricular remodelling. Eur Heart J. 2011;32:1640-8. https://doi.org/10.1093/eurheartj/ehr064.

52. Teh I, McClymont D, Zdora MC, Whittington HJ, Davidoiu V, Lee J, Lygate CA, Rau C, Zanette I, Schneider JE. Validation of diffusion tensor MRI measurements of cardiac microstructure with structure tensor synchrotron radiation imaging. J Cardiovasc Magn Reson. 2017;19:1-14. https:// doi.org/10.1186/s12968-017-0342-x.

53. van Gorkum RJH, von Deuster C, Guenthner C, Stoeck CT, Kozerke S. Analysis and correction of off-resonance artifacts in echo-planar cardiac diffusion tensor imaging. Magn Reson Med. 2020. https://doi.org/10. 1002/mrm.28318.

\section{Publisher's Note}

Springer Nature remains neutral with regard to jurisdictional claims in published maps and institutional affiliations. 